\title{
Programa Voce Melhor
}

\author{
Springer, Maria Celia Scóz; Oyakaua, Daidi; Bertolacini, Yaimi Hitomi; Fontes, Alice \\ Fumie Aita
}

Instituto de Psiquiatria do HC — mcs.springer@gmail.com

INTRODUÇÃO a incessante busca por melhor qualidade de vida, bem estar das pessoas por um lado e a procura por melhoria contínua de produtividade pelas instituições, tem atuado no sentido de eliminar ou mitigar situações de estresse no ambiente de trabalho. Mudanças cada vez mais rápidas, ambientes competitivos, são causas de estresse das pessoas que se manifestam das mais variadas formas, tais como dores musculares, insônia, irritabilidade dentre muitas outras. a massoterapia utiliza técnicas milenares, sendo eficaz na prevenção e recuperação da saúde, conforme a OMS . Nesse sentido, as massagens corporativas shiatsu-express, quick-massage, reflexologia e reset(atm) quando aplicadas no ambiente de trabalho são excelentes para a prevenção de doenças ocupacionais. OBJETIVO Nosso objetivo é melhorar a qualidade de vida no trabalho dos profissionais da saúde, bem-estar, aumento da produtividade, melhora das relações interpessoais, redução de absenteísmo devido a dores musculares e estresse. MÉTODO o PROGRAMA Você Melhor objetiva contribuir nesse processo, conciliando os interesses dos profissionais, utilizando um conjunto de técnicas e ações distribuídas nas seguintes fases: • Fase 1: Terapia Corporal (massoterapia) -3 projetos piloto realizados $\bullet$ Fase 2: Terapia Corporal + Caminhada/Alongamento -- projeto-piloto (inicio 07/02/14) - Fase 3: Terapia Corporal + Caminhada/Alongamento + Ginástica Funcional. Foram aplicadas as seguintes técnicas de massoterapia: shiatsu-express e reset (ATM) em 53 profissionais da área da saúde. Os atendimentos foram realizados no próprio ambiente de trabalho, para diminuir a interferência nas atividades diárias. Cada técnica foi aplicada durante 6 semanas. no $1^{\circ}$ atendimento foi preenchido uma ficha de Anamnese com suas principais queixas. Durante o período do projeto os profissionais receberam as técnicas uma vez por semana e a cada atendimento foi realizado um feedback das queixas apresentadas e avaliadas como melhor, igual ou pior, totalizando 6 atendimentos sequenciais. RESULTADOS Resultados atingidos: Alivio das dores musculares Redução dos sintomas de estresse Maior sensação de bem estar e conforto Melhoria do sistema digestivo Melhoria do humor, disposição física e mental CONCLUSÃo Esses Projetos-Pilotos foram realizados no período de setembro de 2013 a janeiro de 2014 em setores diferentes, totalizando atendimentos em 53 profissionais da área da saúde. Obtivemos $87 \%$ de melhora dos sintomas nos Pilotos ํㅜ 1 e 2 e $81 \%$ de melhora dos sintomas no Piloto ํo 3 . por esta razão já está previsto para início de fevereiro a implantação da Fase 02 do PROGRAMA VOCÉ MELHOR e assim atingirmos cada vez mais uma melhor qualidade de vida no trabalho para os profissionais da saúde.

Springer, Maria Celia Scóz; Oyakaua, Daidi; Bertolacini, Yaimi Hitomi; Fontes, Alice Fumie Aita. Programa Voce Melhor. In: Anais do Congresso Internacional de Humanidades \& Humanização em Saúde [= Blucher Medical Proceedings, num.2, vol.1]. São Paulo: Editora Blucher, 2014. ISSN 2357-7282 DOI 10.5151/medpro-cihhs-10660 